\title{
A Generic Computational Solution of a Natural Convection Flow past an Infinite Vertical Porous Plate
}

\author{
Harouna Naroua, Moussa Idi Bachir \\ Département de Mathématiques et Informatique, Université Abdou Moumouni, Niamey, Niger \\ Email: hnaroua@yahoo.com, bachir.moussaidi@yahoo.fr
}

How to cite this paper: Naroua, $H$. and Bachir, M.I. (2016) A Generic Computational Solution of a Natural Convection Flow past an Infinite Vertical Porous Plate. American Journal of Computational Mathematics, 6, 287-297.

http://dx.doi.org/10.4236/ajcm.2016.64030

Received: August 3, 2016

Accepted: November 8, 2016

Published: November 11, 2016

Copyright $\odot 2016$ by authors and Scientific Research Publishing Inc. This work is licensed under the Creative Commons Attribution International License (CC BY 4.0).

http://creativecommons.org/licenses/by/4.0/

\begin{abstract}
A simulation was carried out on an unsteady flow of a viscous, incompressible and electrically conducting fluid past an infinite vertical porous plate. A generic computer program using the Galerkin finite element method is employed to solve the coupled non-linear differential equations for velocity and temperature fields. The diffusion equation, the energy equation, the momentum equations and other relevant parameters are transformed into interpretable postfix codes. Numerical calculations are carried out on the flow fields both in the presence of cooling and heating of the plate by free convection currents. The effects of the dimensionless parameters, namely, the Prandtl number, the Eckert number, the modified Grashof number, the Schmidt number and the time on the temperature and velocity distributions are discussed.
\end{abstract}

\section{Keywords}

Computer Simulation, Generic Software Tool, Finite Element Method, Laminar Fluid Flow

\section{Introduction}

The effect of an applied magnetic field on unsteady free convection flow along a vertical plate has been given considerable interest because of its application in the cooling of nuclear reactors or in the study of the structures of stars and planets which are greatly influenced by the thermal convection processes in their interiors. A number of authors have made important contributions in that area and in the area of fluid flows in general like [1]-[8]. 
Yusuf et al. [9] used the Modified Adomian Decomposition Method for the first time to obtain the solution to the problem of laminar fluid flow in an inclined parallel wall resulting from the movement of the lower wall while the upper wall remains stationary in a nanofluid with thermal convection, Soret and Dufour effects with radiation. Rectangular coordinates are used in their analysis. Qadri and Krishna [10] considered the flow of an incompressible viscous Maxwell fluid between two parallel plates, initially induced by a constant pressure gradient. They assumed that pressure gradient is withdrawn and the upper plate moves with a uniform velocity while the lower plate continues to be at rest. They defined their run-up flow to be the arising and used the Laplace transform technique in order to solve their initial value problem. The authors calculated the values of the velocity and the shear stresses on the two plates. Aiyesimi et al. [11] presented the magnetohydrodynamic flow of an unsteady convective third grade fluid in a cylindrical system. They used the homotopy perturbation method to analytically solve the non-linear governing equations. The influences of dimensionless parameters on magnetohydrodynamic flow of a convective third grade fluid in a cylindrical system were investigated. Daniel and Seini [12] investigated the effect of inclination on the heat and mass transfer characteristics of a heated plate with viscous dissipation. An incompressible ferrofluid was made to uniformly flow over a heated plate and a transverse magnetic field applied to regulate the flow. Their mathematical model included the equation of mass conservation, the momentum equation, the energy equation and the concentration equation. They made use of the fourth order Runge Kutta method in order to solve the problem.

In this paper, we are making use of a generic computer tool based on the Galerkin finite element method in order to compute the solution of an unsteady boundary layer flow of an incompressible, viscous and electrically conducting fluid past an infinite vertical porous plate.

\section{Mathematical Formulation and Solution of the Problem}

The geometry and the unsteady flow fields for this problem are described by Bitok [13]. After transformation, the problem considered reduces to the following non-dimensional differential equations:

$$
\left\{\begin{array}{l}
\frac{1}{4} S c \frac{\partial C}{\partial t}-S c \frac{\partial C}{\partial y}=\frac{\partial^{2} C}{\partial y^{2}} \\
\frac{1}{4} \operatorname{Pr} \frac{\partial \theta}{\partial t}-\operatorname{Pr} \frac{\partial \theta}{\partial y}-\frac{\partial^{2} \theta}{\partial y^{2}}=\operatorname{PrEC}\left(\left(\frac{\partial u}{\partial y}\right)^{2}+\left(\frac{\partial w}{\partial y}\right)^{2}\right) \\
\frac{1}{4} \frac{\partial u}{\partial t}-\frac{\partial u}{\partial y}-\frac{\partial^{2} u}{\partial y^{2}}+M_{2} u=M_{3} w+M_{2} U+\frac{1}{4} \frac{\partial U}{\partial t}+G r \theta+G c C \\
\frac{1}{4} \frac{\partial w}{\partial t}-\frac{\partial w}{\partial y}-\frac{\partial^{2} w}{\partial y^{2}}+M_{2} w=M_{3}(U-u)
\end{array}\right.
$$

The boundary conditions are given as follows: 


$$
\left\{\begin{array}{l}
u=0, \quad w=0, \quad \theta=1+\varepsilon \mathrm{e}^{\mathrm{i} \omega t}, \quad C=1+\varepsilon \mathrm{e}^{\mathrm{i} \omega t} \quad \text { at } y=0, \\
u \rightarrow 1, \quad w \rightarrow 0, \quad \theta \rightarrow 0, \quad C \rightarrow 0 \quad \text { as } y \rightarrow \infty
\end{array}\right.
$$

and $U=1+\varepsilon \mathrm{e}^{i \omega t}, \quad M_{2}=\frac{M^{2} \lambda^{2}}{1+m^{2} \lambda^{2}}, \quad M_{3}=\frac{M^{2} m \lambda^{3}}{1+m^{2} \lambda^{2}}, \quad \lambda=\cos (\alpha)$

where

- $u$ and $w$ are the components of the dimensionless velocity;

- $\theta$ is the dimensionless temperature;

- $C$ is the dimensionless species concentration;

- $G r$ is the Grashof number;

- $G c$ is the modified Grashof number;

- $\operatorname{Pr}$ is the Prandtl number;

- $E c$ is the Eckert number;

- $S c$ is the Schmidt number;

- $M$ is the magnetic parameter;

- $m$ is the Hall parameter;

- $\alpha$ is the angle of the uniform magnetic field with the $y$-axis.

The system of Equations (1)-(4) with boundary conditions (5) has been solved numerically by a generic computer program based on the finite element method in steps 1 - 3. In all mathematical formulations, $\phi_{i}$ denotes the test function and $\Omega$ is the region of the flow. For each element of the mesh,

$$
\left\{\begin{array}{l}
\phi_{1}^{(i)}(y)=\frac{\left(y_{i+1}-y\right)}{\left(y_{i+1}-y_{i}\right)} \\
\phi_{2}^{(i)}(y)=\frac{\left(y-y_{i}\right)}{\left(y_{i+1}-y_{i}\right)}
\end{array}\right.
$$

where $i=1,2,3, \cdots, N$ and $y_{i}$ and $y_{i+1}$ are respectively the lower and upper coordinates of the element $i$.

Step 1: Diffusion Equation Finite Element Solution

We solve Equation (1) with the help of boundary conditions (5). Constructing the quasi-variational equivalent of Equation (1), we obtain:

$$
0=\int_{\Omega} \phi_{i}\left\{\frac{1}{4} S c \frac{\partial C}{\partial t}-S c \frac{\partial C}{\partial y}-\frac{\partial^{2} C}{\partial y^{2}}\right\} d y
$$

Consider an $N$ elements mesh and a two parameter (semi discrete) Galerkin approximation of the form [14]:

$$
C(y, t)=\sum_{j=1}^{N} d_{j}^{1}(t) \phi_{j}(y)
$$

Using Equations (6) and (8), Equation (7) reduces to:

$$
\left[A^{1}\right]\left\{\frac{\partial d^{1}}{\partial t}\right\}+\left[B^{1}\right]\left\{d^{1}\right\}=\left\{P^{1}\right\}
$$

where 


$$
\left\{\begin{array}{l}
A_{i j}^{1}=\int_{\Omega} \frac{S c}{4} \phi_{i} \phi_{j} \mathrm{~d} y \\
B_{i j}^{1}=\int_{\Omega}\left(\frac{\partial \phi_{i}}{\partial y} \cdot \frac{\partial \phi_{j}}{\partial y}-S c \phi_{i} \frac{\partial \phi_{j}}{\partial y}\right) \mathrm{d} y \\
P_{i}^{1}=0
\end{array}\right.
$$

Using the $\Theta$-family of approximation developed by Reddy [14], Equation (9) reduces to:

$$
\left[\hat{A}^{1}\right]\left\{d^{1}\right\}_{n+1}=\left[\hat{B}^{1}\right]\left\{d^{1}\right\}_{n}+\left\{\hat{P}^{1}\right\}
$$

where

$$
\left\{\begin{array}{l}
{\left[\hat{A}^{1}\right]=\left[A^{1}\right]+\Theta \Delta t\left[B^{1}\right]} \\
{\left[\hat{B}^{1}\right]=\left[A^{1}\right]-(1-\Theta) \Delta t\left[B^{1}\right]} \\
{\left[\hat{P}^{1}\right]=\Delta t\left[\Theta\left\{P^{1}\right\}_{n+1}+(1-\Theta)\left\{P^{1}\right\}_{n}\right]=0}
\end{array}\right.
$$

The initial value $d_{0}^{1}$ is obtained by the Galerkin method from a 64 elements mesh and is given by:

$$
d_{0}^{1}=[1,0,0, \cdots, 0]^{\mathrm{T}}
$$

For $t>0$,

$$
\left\{d^{1}\right\}_{n+1}=\left[\left(\hat{A}^{1}\right)\right]^{-1}\left[\hat{B}^{1}\right]\left\{d^{1}\right\}_{n}+\left[\left(\hat{A}^{1}\right)\right]^{-1}\left\{\hat{P}^{1}\right\}
$$

Step 2: Energy Equation Finite Element Solution

We solve Equation (2) with the help of boundary conditions (5). Constructing the quasi-variational equivalent of Equation (2), we obtain:

$$
0=\int_{\Omega} \phi_{i}\left\{\frac{1}{4} \operatorname{Pr} \frac{\partial \theta}{\partial t}-\operatorname{Pr} \frac{\partial \theta}{\partial y}-\frac{\partial^{2} \theta}{\partial y^{2}}-\operatorname{PrEc}\left(\left(\frac{\partial u}{\partial y}\right)^{2}+\left(\frac{\partial w}{\partial y}\right)^{2}\right)\right\} \mathrm{d} y
$$

Consider an $N$ elements mesh and a two parameter (semi discrete) Galerkin approximation of the form [14]:

$$
\theta(y, t)=\sum_{j=1}^{N} d_{j}^{2}(t) \phi_{j}(y)
$$

Using Equations (6) and (16), Equation (15) reduces to:

$$
\left[A^{2}\right]\left\{\frac{\partial d^{2}}{\partial t}\right\}+\left[B^{2}\right]\left\{d^{2}\right\}=\left\{P^{2}\right\}
$$

where 


$$
\left\{\begin{array}{l}
A_{i j}^{2}=\int_{\Omega} \frac{\operatorname{Pr}}{4} \phi_{i} \phi_{j} \mathrm{~d} y \\
B_{i j}^{2}=\int_{\Omega}\left(\frac{\partial \phi_{i}}{\partial y} \cdot \frac{\partial \phi_{j}}{\partial y}-\operatorname{Pr} \phi_{i} \frac{\partial \phi_{j}}{\partial y}\right) \mathrm{d} y \\
P_{i}^{2}=\int_{\Omega} \operatorname{PrEc} \phi_{i}\left(\left(\frac{\partial u}{\partial y}\right)^{2}+\left(\frac{\partial w}{\partial y}\right)^{2}\right) \mathrm{d} y
\end{array}\right.
$$

Using the $\Theta$-family of approximation developed by Reddy [14], Equation (17) reduces to:

$$
\left[\hat{A}^{2}\right]\left\{d^{2}\right\}_{n+1}=\left[\hat{B}^{2}\right]\left\{d^{2}\right\}_{n}+\left\{\hat{P}^{2}\right\}
$$

where

$$
\left\{\begin{array}{l}
{\left[\hat{A}^{2}\right]=\left[A^{2}\right]+\Theta \Delta t\left[B^{2}\right]} \\
{\left[\hat{B}^{2}\right]=\left[A^{2}\right]-(1-\Theta) \Delta t\left[B^{2}\right]} \\
{\left[\hat{P}^{2}\right]=\Delta t\left[\Theta\left\{P^{2}\right\}_{n+1}+(1-\Theta)\left\{P^{2}\right\}_{n}\right]}
\end{array}\right.
$$

The initial value $d_{0}^{2}$ is obtained by the Galerkin method from a 64 elements mesh and is given by:

$$
d_{0}^{2}=[1,0,0, \cdots, 0]^{\mathrm{T}}
$$

For $t>0$,

$$
\left\{d^{2}\right\}_{n+1}=\left[\left(\hat{A}^{2}\right)\right]^{-1}\left[\hat{B}^{2}\right]\left\{d^{2}\right\}_{n}+\left[\left(\hat{A}^{2}\right)\right]^{-1}\left\{\hat{P}^{2}\right\}
$$

Step 3: Momentum Equations Finite Element Solution

We solve Equations (3), (4) with the help of boundary conditions (5). Constructing the quasi-variational statement of Equations (3), (4), we obtain:

$$
\left\{\begin{array}{l}
0=\int_{\Omega} \phi_{i}\left\{\frac{1}{4} \frac{\partial u}{\partial t}-\frac{\partial u}{\partial y}-\frac{\partial^{2} u}{\partial y^{2}}+M_{2} u-M_{3} w-M_{2} U-\frac{1}{4} \frac{\partial U}{\partial t}-G r \theta-G c C\right\} \mathrm{d} y \\
0=\int_{\Omega} \phi_{i}\left\{\frac{1}{4} \frac{\partial w}{\partial t}-\frac{\partial w}{\partial y}-\frac{\partial^{2} w}{\partial y^{2}}+M_{2} w-M_{3}(U-u)\right\} \mathrm{d} y
\end{array}\right.
$$

Consider an $N$ elements mesh and a two parameter (semi discrete) Galerkin approximation of the form [14]:

$$
\left\{\begin{array}{l}
u(y, t)=\sum_{j=1}^{N} d_{j}^{3}(t) \phi_{j}(y) \\
w(y, t)=\sum_{j=1}^{N} d_{j}^{4}(t) \phi_{j}(y)
\end{array}\right.
$$

Using Equations (6), (25) and (26), Equations (23), (24) reduce to: 


$$
\left\{\begin{array}{l}
{\left[A^{3}\right]\left\{\frac{\partial d^{3}}{\partial t}\right\}+\left[B^{3}\right]\left\{d^{3}\right\}=\left\{P^{3}\right\}} \\
{\left[A^{4}\right]\left\{\frac{\partial d^{4}}{\partial t}\right\}+\left[B^{4}\right]\left\{d^{4}\right\}=\left\{P^{4}\right\}}
\end{array}\right.
$$

where

$$
\left\{\begin{array}{l}
A_{i j}^{3}=\int_{\Omega} \frac{1}{4} \phi_{i} \phi_{j} \mathrm{~d} y \\
B_{i j}^{3}=\int_{\Omega}\left(\frac{\partial \phi_{i}}{\partial y} \cdot \frac{\partial \phi_{j}}{\partial y}-\phi_{i} \frac{\partial \phi_{j}}{\partial y}+M_{2} \phi_{i} \phi_{j}\right) \mathrm{d} y \\
P_{i}^{3}=\int_{\Omega} \phi_{i}\left(M_{3} w+M_{2} U+\frac{1}{4} U_{t}+G r \theta+G c C\right) \mathrm{d} y \\
A_{i j}^{4}=\int_{\Omega} \frac{1}{4} \phi_{i} \phi_{j} \mathrm{~d} y \\
B_{i j}^{4}=\int_{\Omega}\left(\frac{\partial \phi_{i}}{\partial y} \cdot \frac{\partial \phi_{j}}{\partial y}-\phi_{i} \frac{\partial \phi_{j}}{\partial y}+M_{2} \phi_{i} \phi_{j}\right) \mathrm{d} y \\
P_{i}^{4}=\int_{\Omega} M_{3} \phi_{i}(U-u) \mathrm{d} y
\end{array}\right.
$$

Using the $\Theta$-family of approximation developed by Reddy [14], Equations (27), (28) reduce to:

$$
\left\{\begin{array}{l}
{\left[\hat{A}^{3}\right]\left\{d^{3}\right\}_{n+1}=\left[\hat{B}^{3}\right]\left\{d^{3}\right\}_{n}+\left\{\hat{P}^{3}\right\}} \\
{\left[\hat{A}^{4}\right]\left\{d^{4}\right\}_{n+1}=\left[\hat{B}^{4}\right]\left\{d^{4}\right\}_{n}+\left\{\hat{P}^{4}\right\}}
\end{array}\right.
$$

where

$$
\left\{\begin{array}{l}
{\left[\hat{A}^{3}\right]=\left[A^{3}\right]+\Theta \Delta t\left[B^{3}\right]} \\
{\left[\hat{B}^{3}\right]=\left[A^{3}\right]-(1-\Theta) \Delta t\left[B^{3}\right]} \\
{\left[\hat{P}^{3}\right]=\Delta t\left[\Theta\left\{P^{3}\right\}_{n+1}+(1-\Theta)\left\{P^{3}\right\}_{n}\right]} \\
{\left[\hat{A}^{4}\right]=\left[A^{4}\right]+\Theta \Delta t\left[B^{4}\right]} \\
{\left[\hat{B}^{4}\right]=\left[A^{4}\right]-(1-\Theta) \Delta t\left[B^{4}\right]} \\
{\left[\hat{P}^{4}\right]=\Delta t\left[\Theta\left\{P^{4}\right\}_{n+1}+(1-\Theta)\left\{P^{4}\right\}_{n}\right]}
\end{array}\right.
$$

The initial values $d_{0}^{3}$ and $d_{0}^{4}$ are obtained by the Galerkin method from a 64 elements mesh and are given by:

$$
\left\{\begin{array}{l}
d_{0}^{3}=[0,0,0, \cdots, 1]^{\mathrm{T}} \\
d_{0}^{4}=[0,0,0, \cdots, 0]^{\mathrm{T}}
\end{array}\right.
$$

For $t>0$,

$$
\left\{\begin{array}{l}
\left\{d^{3}\right\}_{n+1}=\left[\left(\hat{A}^{3}\right)\right]^{-1}\left[\hat{B}^{3}\right]\left\{d^{3}\right\}_{n}+\left[\left(\hat{A}^{3}\right)\right]^{-1}\left\{\hat{P}^{3}\right\} \\
\left\{d^{4}\right\}_{n+1}=\left[\left(\hat{A}^{4}\right)\right]^{-1}\left[\hat{B}^{4}\right]\left\{d^{4}\right\}_{n}+\left[\left(\hat{A}^{4}\right)\right]^{-1}\left\{\hat{P}^{4}\right\}
\end{array}\right.
$$


The numerical values of the temperature and velocity fields have been computed from equations (14), (22), (35) and (36). All input elements such as matrix and vector elements are transformed into interpretable postfix codes.

\section{Discussion of Results}

Numerical calculations have been carried out for the velocity and temperature distributions. The analysis of Bitok [13] was restricted to the behaviour of the flow fields with respect to the angle $\alpha$ and the Hall parameter $m$. We are proposing a more complete analysis and the results obtained are displayed in Figures 1-4. The method used is unconditionally stable and is independent of the time step $\Delta t$. The velocity profiles are examined for the cases $G r>0$ and $G r<0 . G r>0(=+10)$ is used for the case when the flow is in the presence of cooling of the plate by free convection currents. $G r<0(=-10)$ is used for the case when the flow is in the presence of heating of the plate by free convection currents. The values of $\lambda(\lambda=1)$ and $m(m=1)$ are kept constant during the simulation while series of values for the other dimensionless parameters are used as shown in Figures 1-4.

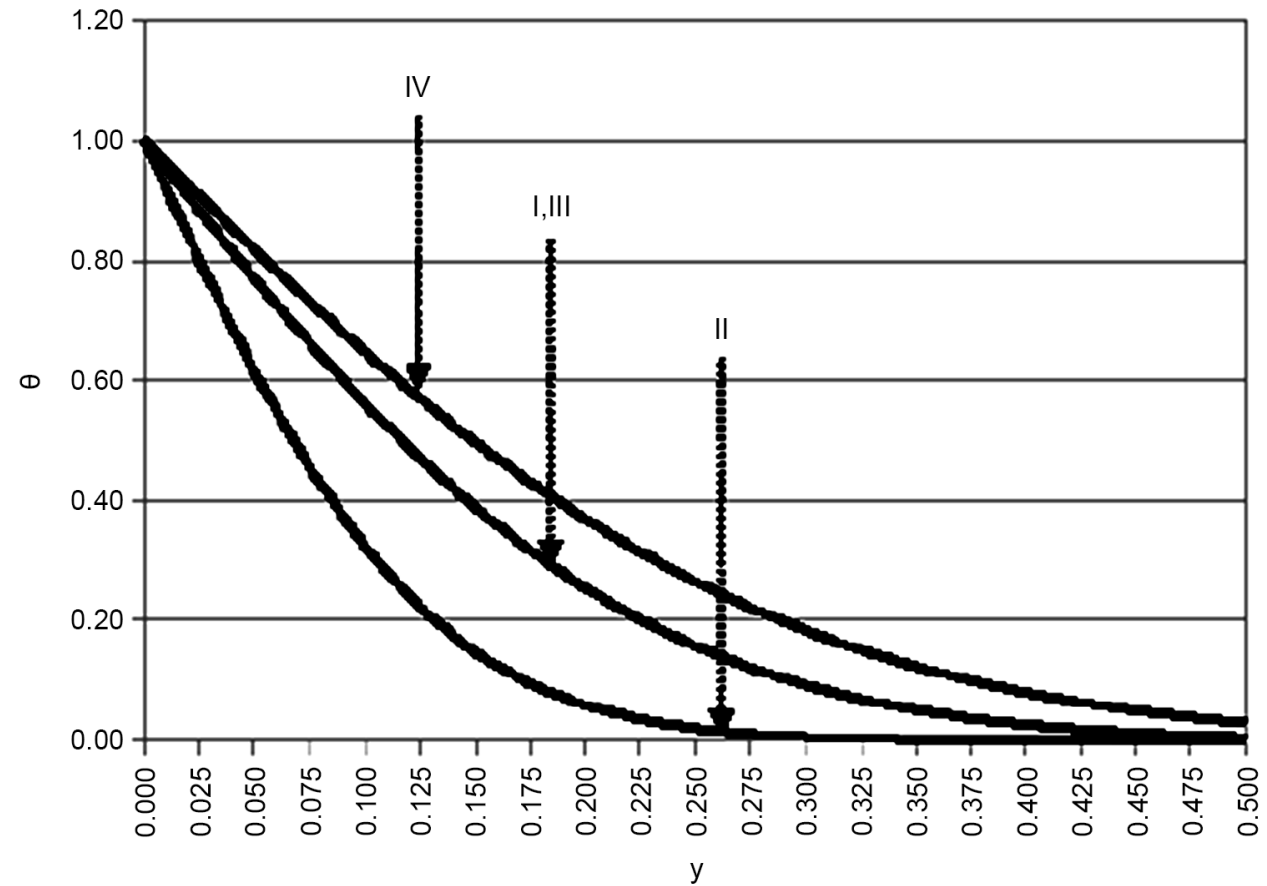

\begin{tabular}{|c|c|c|c|}
\hline Series & $\operatorname{Pr}$ & Ec & $\boldsymbol{t}$ \\
\hline I & 0.83 & 0.01 & 0.001 \\
\hline II & 7.00 & 0.01 & 0.001 \\
\hline III & 0.83 & 0.05 & 0.001 \\
\hline IV & 0.83 & 0.01 & 0.005 \\
\hline
\end{tabular}

Figure 1. Temperature distribution for $G r= \pm 10$. 
From Figure 1, it is observed that:

1) The temperature $(\theta)$ decreases away from the plate. The decrease is greater for a Newtonian fluid than it is for a non-Newtonian fluid ( $\theta$ decreases with $P r)$;

2) There is a rise in temperature profiles $(\theta)$ due to an increase in the time $(t)$;

3) There is an insignificant change in the temperature profiles $(\theta)$ due to an increase in the Eckert number $(E c)$.

From Figure 2, for the case when $G r>0$ (in the presence of cooling of the plate by free convection currents), it is observed that:

1) The primary velocity $(u)$ decreases due to an increase in the Prandtl number $(P r)$ and the Schmidt number $(S c)$;

2) An increase in the modified Grashof number $(G c)$ and the time $(t)$ leads to a rise in the primary velocity $(u)$;

3) There is an insignificant change in the primary velocity $(u)$ due to an increase in the Eckert number $(E c)$.

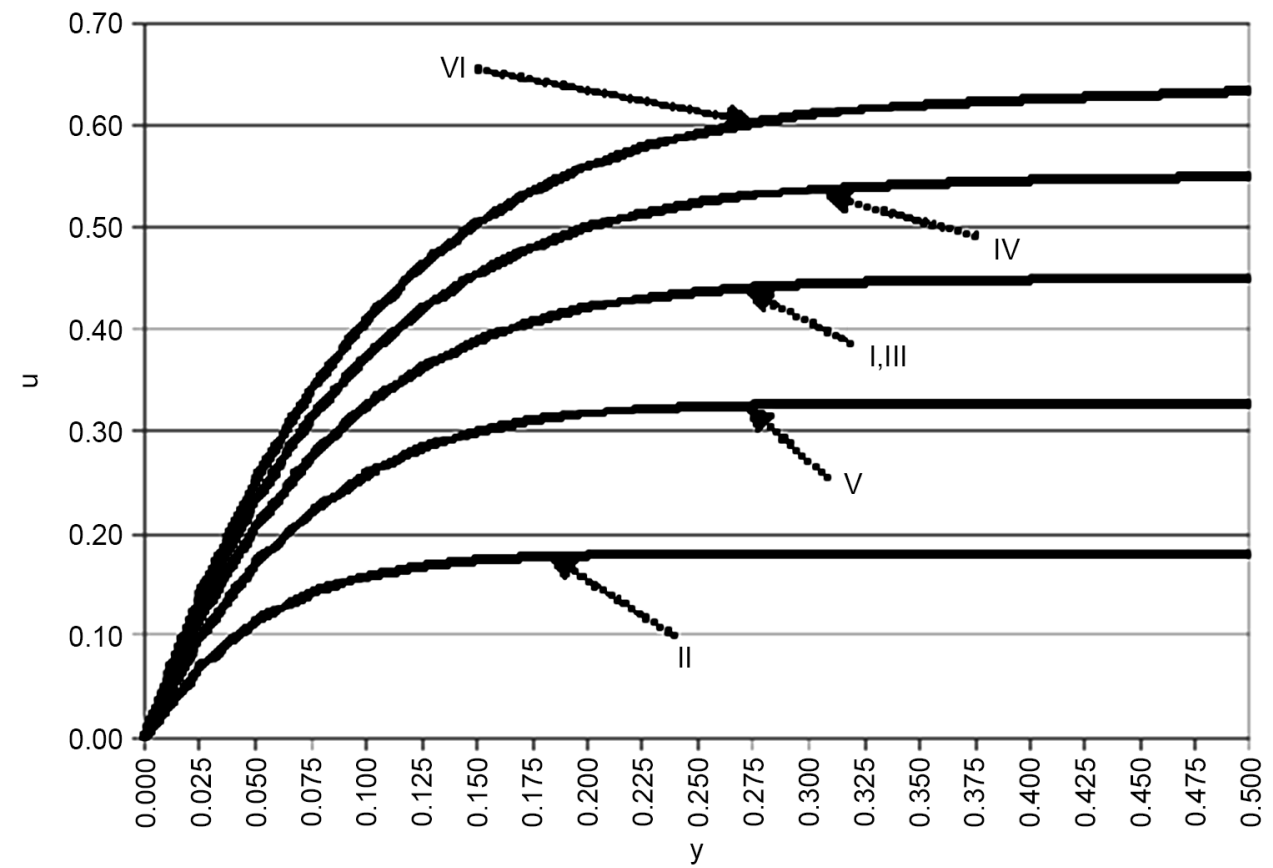

\begin{tabular}{|c|c|c|c|c|c|}
\hline Series & $P r$ & $E c$ & Gc & Sc & $t$ \\
\hline I & 0.83 & 0.01 & 2 & 0.60 & 0.001 \\
\hline II & 7.00 & 0.01 & 2 & 0.60 & 0.001 \\
\hline III & 0.83 & 0.05 & 2 & 0.60 & 0.001 \\
\hline IV & 0.83 & 0.01 & 3 & 0.60 & 0.001 \\
\hline $\mathrm{V}$ & 0.83 & 0.01 & 2 & 0.80 & 0.001 \\
\hline $\mathrm{VI}$ & 0.83 & 0.01 & 2 & 0.60 & 0.005 \\
\hline
\end{tabular}

Figure 2. Primary velocity distribution for $G r=+10$. 
From Figure 3, for the case when $G r<0$ (in the presence of heating of the plate by free convection currents), it is observed that:

1) The primary velocity $(u)$ decreases due to an increase in the Schmidt number $(S c)$;

2) An increase in the Prandtl number $(P r)$, the modified Grashof number $(G c)$ and the time $(t)$ leads to a rise in the primary velocity $(u)$;

3) There is an insignificant change in the primary velocity $(u)$ due to an increase in the Eckert number $(E c)$.

From Figure 4, for both cases when $G r>0$ (in the presence of cooling of the plate by free convection currents) and $G r<0$ (in the presence of heating of the plate by free convection currents), it is observed that:

1 ) The secondary velocity profile $(w)$ increases due to an increase in the time $(t)$;

2) An increase in the Prandtl number $(P r)$, the Eckert number $(E c)$, the modified Grashof number $(G c)$ and the Schmidt number $(S c)$ leads to an insignificant change in the secondary velocity profile $(w)$.

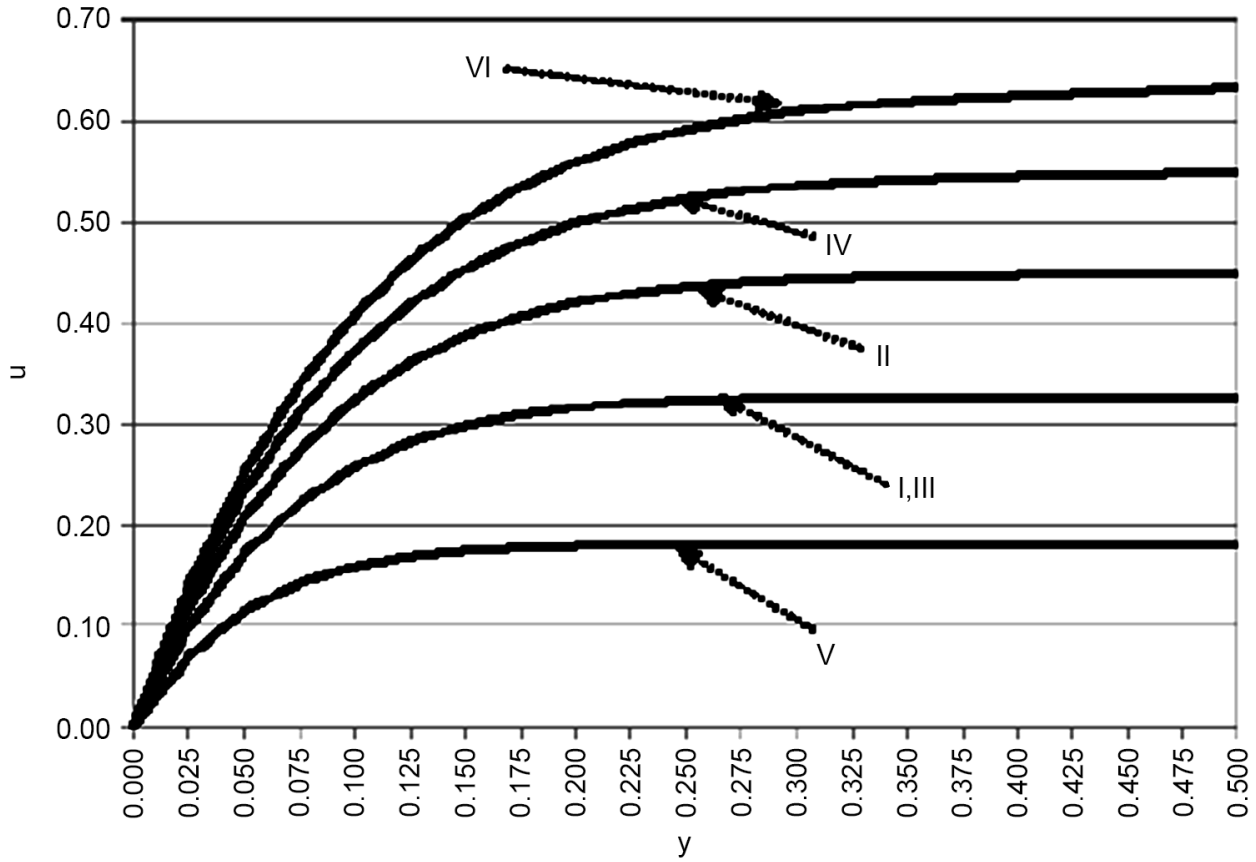

\begin{tabular}{|c|c|c|c|c|c|}
\hline Series & $P r$ & $E c$ & $G c$ & $S c$ & $t$ \\
\hline I & 0.83 & 0.01 & 2 & 0.60 & 0.001 \\
\hline II & 7.00 & 0.01 & 2 & 0.60 & 0.001 \\
\hline III & 0.83 & 0.05 & 2 & 0.60 & 0.001 \\
\hline IV & 0.83 & 0.01 & 3 & 0.60 & 0.001 \\
\hline $\mathrm{V}$ & 0.83 & 0.01 & 2 & 0.80 & 0.001 \\
\hline $\mathrm{VI}$ & 0.83 & 0.01 & 2 & 0.60 & 0.005 \\
\hline
\end{tabular}

Figure 3. Primary velocity distribution for $G r=-10$. 


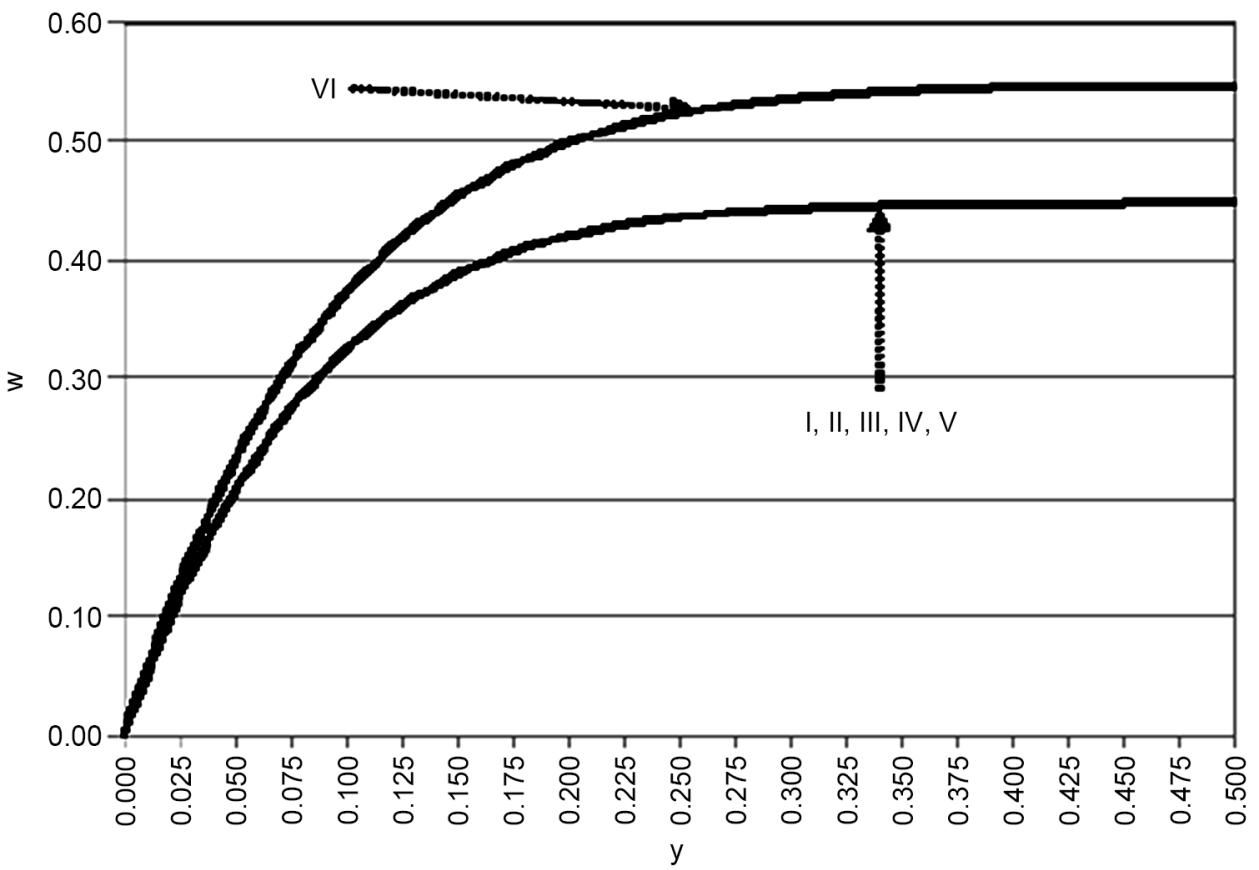

\begin{tabular}{|c|c|c|c|c|c|}
\hline Series & $P r$ & Ec & Gc & Sc & $t$ \\
\hline I & 0.83 & 0.01 & 2 & 0.60 & 0.001 \\
\hline II & 7.00 & 0.01 & 2 & 0.60 & 0.001 \\
\hline III & 0.83 & 0.05 & 2 & 0.60 & 0.001 \\
\hline IV & 0.83 & 0.01 & 3 & 0.60 & 0.001 \\
\hline $\mathrm{V}$ & 0.83 & 0.01 & 2 & 0.80 & 0.001 \\
\hline $\mathrm{VI}$ & 0.83 & 0.01 & 2 & 0.60 & 0.005 \\
\hline
\end{tabular}

Figure 4. Secondary velocity distribution for $G r= \pm 10$.

\section{Conclusion}

In this work, a computer simulation was carried out on the unsteady flow of a viscous, incompressible and electrically conducting fluid past an infinite vertical porous plate. The velocity and the temperature fields were computed using a generic software tool based on the Galerkin finite element method. The results obtained reveal that the use of interpretable codes provides a good solution to fluid flow problems.

\section{References}

[1] Soundalgekar, V.M. and Takhar, H.S. (1980) Combined Forced and Free Convection MHD Flow past a Semi-Infinite Vertical Plate. Wärmeund Stoffübertragung, 14, 153-158. http://dx.doi.org/10.1007/BF01637696

[2] Bestman, A.R. and Adiepong, S.K. (1988) Unsteady Hydromagnetic Free-Convection Flow with Radiative Heat Transfer in a Rotating Fluid. Astrophysics and Space Science, 143, 7380. http://dx.doi.org/10.1007/BF00636756 
[3] Brewster, M.Q. (1992) Thermal Radiative Transfer and Properties. John Wiley and Sons, New York.

[4] Raptis, A. and Massalas, C.V. (1997) Magnetohydrodynamic Flow past a Plate by the Presence of Radiation. Journal of Magnetohydrodynamics and Plasma Research, 7, 121-128.

[5] Yamauchi, J., Nakamura, S. and Nakano, H. (2000) Application of Modified Finite-Difference Formulas to the Analysis of $\mathrm{z}$-Variant Rib Waveguides. IEEE Photonics Technology Letters, 12, 1001-1003. http://dx.doi.org/10.1109/68.867988

[6] Raptis, A. and Perdikis, C. (2003) Thermal Radiation of an Optically Thin Gray Gas. International Journal of Applied Mechanics and Engineering, 8, 131-134.

[7] Zhu, S., Yuan, G. and Sun, W. (2004) Convergence and Stability of Explicit/Implicit Schemes for Parabolic Equations with Discontinuous Coefficients. International Journal of Numerical Analysis and Modeling, 1, 131-145.

[8] Khader, M.M. and Ahmed, M.M. (2013) Numerical Simulation Using the Finite Difference Method for the Flow and Heat Transfer in a Thin Liquid Film over an Unsteady Stretching Sheet in a Saturated Porous Medium in the Presence of Thermal Radiation. Journal of King Saud University-Engineering Sciences, 25, 29-34. http://dx.doi.org/10.1109/68.867988

[9] Yusuf, A., Aiyesimi, Y.M., Jiya, M. and Okedayo, G.T. (2016) Analysis of Couette Flow of a Nanofluid in an Inclined Channel with Soret and Dufour Effects. American Journal of Computational and Applied Mathematics, 6, 57-64.

[10] Qadri, S.Y. and Krishna, M.V. (2013) Run-Up Flow of a Maxwell Fluid through a Parallel Plate Channel. American Journal of Computational Mathematics, 3, 297-303. http://dx.doi.org/10.4236/ajcm.2013.34039

[11] Aiyesimi, Y.M., Jiya, M., Olayiwola, R.O. and Wachin, A.A. (2016) Mathematical Analysis of Convective Flow of an Unsteady Magnetohydrodynamic (MHD) Third Grade Fluid in a Cylindrical Channel. American Journal of Computational and Applied Mathematics, 6, 103-108.

[12] Daniel, A.A. and Seini, Y.I. (2016) MHD Boundary Layer Flow past an Inclined Plate with Viscous Dissipation. American Journal of Computational and Applied Mathematics, 6, 149-161.

[13] Bitok, J.K. (1998) The Effects of Hall Current on Natural Convection Flow with Mass Transfer. Journal of Magnetohydrodynamics and Plasma Research, 7, 227-256.

[14] Reddy, J.N. (1984) An Introduction to the Finite Element Method. Mc Graw Hill Book Company, Singapore. 
Submit or recommend next manuscript to SCIRP and we will provide best service for you:

Accepting pre-submission inquiries through Email, Facebook, LinkedIn, Twitter, etc.

A wide selection of journals (inclusive of 9 subjects, more than 200 journals)

Providing 24-hour high-quality service

User-friendly online submission system

Fair and swift peer-review system

Efficient typesetting and proofreading procedure

Display of the result of downloads and visits, as well as the number of cited articles

Maximum dissemination of your research work

Submit your manuscript at: http://papersubmission.scirp.org/

Or contact ajcm@scirp.org 